IZA DP No. 9982

Group (Re-)formation in Public Good Games:

The Tale of the Bad Apple

Christian Grund

Christine Harbring

Kirsten Thommes

June 2016 


\title{
Group (Re-)formation in Public Good Games: The Tale of the Bad Apple
}

\author{
Christian Grund \\ RWTH Aachen University and IZA \\ Christine Harbring \\ RWTH Aachen University \\ Kirsten Thommes \\ Brandenburg University of Technology Cottbus
}

Discussion Paper No. 9982

June 2016

IZA

P.O. Box 7240

53072 Bonn

Germany

Phone: +49-228-3894-0

Fax: +49-228-3894-180

E-mail: iza@iza.org

Any opinions expressed here are those of the author(s) and not those of IZA. Research published in this series may include views on policy, but the institute itself takes no institutional policy positions. The IZA research network is committed to the IZA Guiding Principles of Research Integrity.

The Institute for the Study of Labor (IZA) in Bonn is a local and virtual international research center and a place of communication between science, politics and business. IZA is an independent nonprofit organization supported by Deutsche Post Foundation. The center is associated with the University of Bonn and offers a stimulating research environment through its international network, workshops and conferences, data service, project support, research visits and doctoral program. IZA engages in (i) original and internationally competitive research in all fields of labor economics, (ii) development of policy concepts, and (iii) dissemination of research results and concepts to the interested public.

IZA Discussion Papers often represent preliminary work and are circulated to encourage discussion. Citation of such a paper should account for its provisional character. A revised version may be available directly from the author. 
IZA Discussion Paper No. 9982

June 2016

\section{ABSTRACT \\ Group (Re-)formation in Public Good Games: The Tale of the Bad Apple}

We analyze how different previous roles as partners or strangers in public good games affect an individual's subsequent cooperation in a partner setting. We systematically vary a group's composition from all individuals being partner over blended groups of partners and strangers to all individuals being stranger in each round. Our results show that previous group composition does not affect cooperation in the subsequent partner setting with one exception: Groups cooperate significantly less compared to all other settings, when one stranger entered the group. We further analyze this situation in-depth and find that individuals may labor under an ultimate attribution error: They feel that the newcomer is a "bad apple". The cooperativeness towards the newcomer, but also among oldtimers is disturbed in this case. We conduct additional treatments to back up this result and to show how certain information can prevent such an error.

JEL Classification: $\quad$ C9, M5

Keywords: cooperation, economic experiments, group composition, public good game, teams

Corresponding author:

Christian Grund

RWTH Aachen University

Chair of Human Resource Management and Personnel Economics

Templergraben 64

52056 Aachen

Germany

E-mail: christian.grund@rwth-aachen.de 


\section{Group (Re-) formation in Public Good Games: The Tale of the Bad Apple}

\section{Introduction}

Achieving a high level of cooperation among members of a group is an essential objective within and outside of organizations. In many organizational instances, though, working groups have to be reassembled every now and then. This is true for regular work groups as well as for groups with changing members (e.g. due to shift work, job rotation or flexible staffing) or groups formed for a limited duration, such as a project team.

Not surprisingly, teamwork and cooperation failures are prominent topics in the economics and management literature. Based on the seminal article in the economics literature by Alchian \& Demsetz (1972) on the problem of free-riding in teams, scholars have analyzed possible solutions to the cooperation problem both theoretically (e.g. Holmström 1982, Kendal \& Lazear 1992, Che \& Yoo 2001, Guillen et al. 2015) and empirically mostly in controlled experimental settings that investigate the effects of certain types of incentives and sanctions in public good games (Fehr and Gächter 2000, Masclet et al. 2003, see for a review Chaudhuri 2011, ).

However, we still know little about the question of how to assign individuals to working groups that best enhance cooperation, especially in cases where individuals' time horizons and histories differ from those of others in the group. In most working groups, the composition is fluid, i.e., there are group members who continuously stay with the group and others who switch groups repeatedly, entering a group as a newcomer. Such settings are well reflected by those organizational practices geared towards flexibility such as temporary contracts (Kalleberg 2000) or organizational project management (Huckman et al. 2009). Hence, the issue of group formation and group reformation if temporary group members are switched or become permanent members in the present or another group are both theoretically and practically relevant. However, the consequences of such practices are still not well understood: What consequences does group fluidity have on cooperation?

Recent experimental research suggests that temporary group membership significantly lowers cooperation in groups (Grund et al. 2015). If this is true, the question arises of whether groups with alternating temporary group members can recover once the group has been restructured to one with permanent group membership only. If groups cannot easily recover from a temporary group member, temporary group membership might turn out as to be double-edged sword: While it increases flexibility and potentially gives access to more and broader knowledge (Choi and Thompson 2005, Rink and Ellemers 2009), it might also have severe consequences for productivity not only during the employment of the temporary group member (Rink and Ellemers 2009, Grund et al. 2015), but also in the aftermath. Note that our work focuses on the frequency and duration of interaction within the group, i.e. the group 
matching procedure while Charness, Rigotti, and Rustichini (2007) systematically vary group membership associated with a certain degree of group identification and find that this may affect cooperation. ${ }^{1}$

Experimental studies seem to be an ideal tool for analyzing the impact of group membership on cooperation, as the matching of participants to groups can easily be varied ceteris paribus. Thus, it is not surprising that there are already some interesting experiments that focus on group membership in public good games (Fehr \& Gächter 2000, Keser \& van Winden 2000 and for an excellent overview, Andreoni \& Croson 2008). Though, to the best of our knowledge, only homogeneous groups are investigated in this literature, i.e., groups with permanent members ("partners", who stay with the group over rounds) or temporary members only ("strangers", who are randomly assigned to a new group in each period). There is one recent exception to the homogeneity paradigm with respect to different time horizons: Grund et al. (2015) have extended the group composition to blended groups with one or two strangers, who are randomly allocated to different groups of three or two partners in each round. They examine the effects of group composition on cooperation by analyzing the different ratios of partners and strangers in a public good game. They find that individuals who are temporary members of the group cooperate significantly less than permanent members. Moreover, individual cooperation increases with the number of the same type of player in a group. However, we do not know yet whether and how groups can recover from temporary group members.

We close a gap in the literature by analyzing how individuals' past experiences in a specific group affect cooperation in newly formed groups with permanent members only. ${ }^{2}$ In our study, differently composed groups repeatedly contribute to a public good in a first part; in the second part of the experiment, we convert all groups into a partner setting with only permanent members. By comparing behavior in the second part, we can analyze the impact of previous experiences and group composition on current behavior. We elicit beliefs to check for individuals' expectations towards others, also dependent on the type of group membership. We analyze the results on the individual level as well as on the group level.

We find some differences in cooperation behavior over the first part, where participants are exposed to differently composed groups, as already reported by Grund et al. (2015). In the second part, where all subjects are in groups with permanent members only we observe virtually no differences in contributions There is one exception, though. While all groups increase their contributions after being converted into a group with permanent members, the group with just one temporary member decreases cooperation on average from the first to the second part. A closer look at contributions over time as well as beliefs towards others surprisingly indicates that this effect is primarily initiated by the three participants who were permanent members in the first part. After a temporary member has been assigned to the group as a permanent member, these subjects start off with lower contributions than the temporary

\footnotetext{
1 We exogenously assign participants to groups. For an interesting experiment on public good games with endogenous group formation see Gürerk et al. (2014).

2 There are already interesting studies on the effect of workplace organizations and respective work norms showing that being exposed to a certain instutional environment may impact behavior in new unrelated settings, e.g. Gneezy et al. (2015).
} 
member, which is also reflected by their beliefs. Not only is their cooperativeness towards the new team member disturbed, but also their cooperativeness among each other: In this specific treatment, direct reciprocity among the permanent group members is severely disturbed, resulting in a contagious effect of declining cooperation.

In order to better understand the situation with one newcomer in the group, we conducted additional treatments. We learn from these treatments that participants attribute the lower contributions in the first part rather to the specific subjects in the role of temporary group members, with whom they had interacted, rather than to the circumstances, i.e. the exogenously given group composition. This is known as an ultimate attribution error in social psychology (Pettigrew 1979) and reflected in the "bad apple" phenomenon in the economic literature on cooperation (de Oliveira et al. 2014). We therefore conclude that the subsequent cooperation problems are not due to the one "bad apple" in the group but to the attribution error of permanent members, who believe that they had a "bad apple" in their group and who do not perceive it having one of these subjects permanently in the group as good news. We conclude that besides to the relevance of bad apples for decreased cooperation in groups (see Felps et al. 2006, Kerr et al. 2009, de Oliveira et al. 2014), it is also a "bad barrel" in terms of the history of the structure of group composition that matters.

The remainder of our paper is as follows: We discuss the relevant literature and subsequently present our experimental design. After presenting the results of our four main treatments we give insight into the findings of two additional treatments. We conclude with a summary and a discussion of our analysis.

\section{Related Literature}

In recent years, various reviews and meta-studies significantly have improved our understanding of team work productivity from various disciplines, such as social psychology (e.g. Ilgen et al. 2005, Kozlowski and Ilgen 2006), management research (e.g. Mathieu et al. 2008, Joshi \& Roh 2009, Mathieu et al. 2014), and also medical science (e.g. Lemieux-Charles \& McGuire 2006, Xyrichis \& Lowton 2008). The changing of group membership (Huckman et al. 2009) and group composition should deserve our attention, as it might significantly affect productivity (see, for a classification of group compositions, Mathieu et al. 2013). However, as Kozlowski and Bell (2003: 365) note, "[Changes in group composition over time are] - with few exceptions - poorly represented in theory and is virtually ignored in research that is largely based on cross-sectional methodologies”. Changing group compositions over time, however, may alter a group in three different ways ceteris paribus: First, it divides up a group according to the entry of its individual members, splitting any group into newcomers and oldtimers and creating potential fault lines. Second, it implies the newcomers' adaptation to the new group. And third, there is also old group members' adjustment to the new situation. Effects on cooperation thus do not solely result from the newcomer; also altered cooperation levels of oldtimers are very likely (McCarter and Sheremeta 2013). 
As outlined above, there is already an important strand of literature on experimental studies, which analyze different matching procedures to groups in public good games (\& Andreoni \& Croson 2008). They differentiate between "strangers", who are randomly re-matched to a new group in each round, and "partners", who stick with the same group over rounds. In these studies, groups with only partners or only strangers are analyzed and compared with each other. However, there is no consistent result in the literature. While economic intuition tells us that repeated partner play should facilitate cooperation, since participants may build up reputation and trust (Keser \& van Winden 2000), some studies find that cooperation is higher in groups with strangers only (e.g. Palfrey \& Prisbey 1996). Andreoni \& Croson (2008) explain this finding by the idea that there is more variance in contributions if subjects are re-matched in each round. What is virtually almost unexplored is the investigation of blended groups with partners and strangers and the impact of changing group membership.

The one exception we are aware of is Grund et al. (2015), whose study is closely related to ours. ${ }^{3}$ They observe that individuals in blended groups of partners and strangers in a public-good setting contribute less to a public good compared to the case of groups with four partners only. They compare treatments with zero, one, two and four strangers and find that even one stranger leads to a significantly lower mean contribution in repeated public good games. The question arises, however, of whether this group composition with respect to stability and experienced cooperation also affects future behavior. That is what we address in this contribution.

Our research is also related to other experimental studies on history effects. Based on insights from a study by Ahn et al. (2001), who stress that past play is relevant for future behavior in social dilemmas, we assume past cooperation levels that have been experienced in a group to have an effect on subsequent behavior in a newly composed group. For example, if participants have encountered a low level of cooperation in the past, they may also cooperate less in a newly formed group due to reciprocity towards permanent group members or due to an acquired social norm (Nalbantian and Schotter 1997).

Recent empirical research on team performance underpins the notion of temporal dynamics in group membership in the context of "fluid groups" that are repeatedly reshuffled: Huckman et al. (2009) stress that fluidity is the rule rather than the exception in work groups. In their insightful study on the impact of team familiarity - defined as having joint group experience with current members - on group performance in the software sector, they especially take different degrees of group members' familiarity with each other to center stage. Previous joint group experience may then be the base for trust and present reciprocal behavior. Additionally, related constructs such as social identity

\footnotetext{
${ }^{3}$ Angelova, Güth \& Kocher (2012) also analyze temporary employment, but compare agents' efforts directly without teaming them up. For an experimental analysis of long-term employment relations, see Berninghaus, Bleich \& Güth (2013). Both papers have a related research question, but a very different experimental set-up without a group setting.
} 
(Tajfel and Turner 1979) may be relevant. Whereas familiarity refers to personal relationships, social identity in groups can be fostered by having the same roles. ${ }^{4}$

Aiming at exploring how fluidity in group composition impacts outcome, psychological research assumes, that group receptivity, defined as “a team’s willingness to accept a newcomer as a full team member” (Rink et al. 2013: 249), significantly impacts group productivity after a member change and that receptivity is strongly associated with a group's past performance: Especially well functioning groups deteriorate in productivity after group membership turnover, while less well functioning groups might even be able to edge forward in productivity (Levine et al. 2005). However, in most empirical studies, past performance cannot easily be observed and therefore is missing as one of the most important determinants of group productivity after turnover.

McCarter and Sheremeta (2013) conduct an insightful experiment on the effects of newcomers in coordination games. They show that new group members significantly lower trust in a group and that eventually also the coordination level declines. In their study, they evaluate how information about the newcomers' and the oldtimers' past performance can mitigate the effects, and they find that newcomers in groups always lead to a decline in coordination which can be well explained by trust. Since knowledge bases of individuals cannot serve as a possible explanation for significant differences in outcomes, group stability on its own is shown to have an impact on collaboration. This result may serve as a first hint that instability or fluidity in group composition has a negative effect on collaboration, even when the possibility of knowledge inflows and outflows is ruled out such as in a laboratory setting.

In a very rich study of underground coal mining crews, Goodman and Leyden (1991) observe that familiarity among group members gained from previous work experiences significantly improves performances of crews while turnover in group membership is associated with lowered productivity. Accordingly, Hinds et al. (2000) find that if individuals can compose working groups, they tend to favor former colleagues. However, in most working situations individuals cannot choose their fellow group members but are assigned to teams. Still, psychological research on group performance frequently reveals that familiarity among group members leads to higher performance, especially if the group gained their familiarity on a related task (Littlepage et al. 1997). The assumption that task- and group familiarity are complementary was, however, recently challenged by Espinosa et al. (2010) who report that in their study of software development teams, task- and group familiarity were substitutes rather than complements: The effect of group familiarity was especially strong, if task-familiarity was low. Research on project management and project staffing takes up these findings of psychological literature and confirms that trust among project members is crucial for project performance and that stability in group composition is the main

\footnotetext{
${ }^{4}$ For an interesting analysis of the role of identity on behavior in public good games, see Charness, Cobo-Reyes \& Jimenez (2014). Feri et al. (2010) have shown that teams rather focus on payoff-maximizing strategies compared to individuals in the context of coordination games. Thus, participants may decide for more efficient strategies if they identify as being members of one group.
} 
determinant of trust among project team members (Maurer 2010, Haas 2006). This is very much in line with the study by McCarter and Sheremeta (2013) who also assume trust to be the conceptual reason for the positive impact of familiarity on productivity. Based on this reasoning, we also presume that the more familiar group members are with each other, the higher their cooperation levels are after new group members have entered the group.

Moreover, this past research suggests that independently from who exactly new group members are and what they know, groups might be differently able and willing to cooperate with a new team member. While McCarter and Sheremata (2013) highlight the role of familiarity on group outcome after integrating one newcomer, Grund et al. (2015) stress that cooperation levels are directly affected by group composition. This, in turn might again affect a group’s future ability or willingness to cooperate with newcomers.

\section{Experimental Design and Procedure}

We analyze the relation of group re-formation and cooperation in a controlled laboratory experiment using a public good game to sketch a social dilemma problem. In our study we analyze a setting over two parts by implementing a public good game as in the seminal paper by Fehr and Gächter (2000): In part I participants repeatedly contribute to a public good game. We vary the group composition over the experimental treatments from a setting with partners being permanent members of the group only, over blended groups with one or two strangers to a group of strangers only who are randomly rematched to a new group in each round. In part II of the experiment participants are all assigned to groups with which they permanently stick with the group and repeatedly make their decision in the public good game, i.e., a partner setting. Thus, we examine the impact of the conversion from temporary into permanent group membership.

Subjects form groups of four, and each subject has to individually decide how much of her 20 ECU endowment she wants to invest into the public good project and how much she wants to put aside into her private account. Investments into the public good project are multiplied by 1.6, and the resulting amount is equally re-distributed to each of the four subjects. Savings to the private account remain stable in value and are paid out only to the subject to whom the private account belongs.

Subjects play the public good game over two parts, each consisting of 10 rounds. We conduct four treatments (see also Table 1). In the first ten rounds (part I) group composition differs across treatments as follows: In the partner setting (PPPP), all four subjects form a group of permanent members over the course of 10 rounds. In the stranger setting (SSSS), all subjects are re-allocated to new group members after each round. We introduce two further treatments with blended groups in which (i) one group member is re-allocated randomly to a new group after each round, while three subjects remain together over the 10 rounds (PPPS) and (ii) two subjects switch randomly and independently from one another (PPSS). 
Group composition is the same in all treatments in part II of the experiment, i.e., all subjects are assigned to groups of permanent members only. All players of type P in part I are allocated to their former team mates of type P in part II, whereas former type S players are randomly assigned to a group in round 11 and continue in that group until the end of part II. Hence, there is a conversion of group composition for the groups with strangers PPPS, PPSS, and SSSS, whereas subjects in PPPP face no change. Note that we refer to the types of players in part I whenever we analyze the different types of players (S or P) as players are all partners in part II.

\begin{tabular}{|c|c|c|c|c|c|}
\hline Treatment & \multicolumn{2}{|c|}{$\begin{array}{l}\text { Part I } \\
\text { Round 1-10 }\end{array}$} & & \multicolumn{2}{|c|}{$\begin{array}{l}\text { Part II } \\
\text { Round 11-20 }\end{array}$} \\
\hline I & a) & PPPP & 하 & b) & PPPP \\
\hline II & a) & PPPS & 8 & b) & PPPP \\
\hline III & a) & PPSS & & b) & PPPP \\
\hline IV & a) & SSSS & & b) & РPРP \\
\hline
\end{tabular}

Notes: $\mathrm{P}=$ Partner, $\mathrm{S}=$ Stranger.

\section{Table 1: Experimental Design}

We focus on the analysis of cooperation in part II (in relation to former behavior and types in part I). Our objective is to explore, to what extent contributions to the public good in the partner setting are affected by (1) experiences in a preceding group composition, (2) being of a specific type of player and (3) the number of group members with one who is already familiar with from part I of the experiment.

The eight sessions with 28 subjects each took place between October 2013 and July 2014 in the AIXperiment laboratory located at RWTH Aachen University, Germany. Recruitment was made via ORSEE (Greiner 2004) and the experiment was conducted with z-Tree (Fischbacher 2007). Before the experiment started, subjects were informed about their own type (P or S) and also about their group composition (PPPP, PPPS, PPSS or SSSS) in the first ten rounds. All participants were also informed about their group composition PPPP in the second ten rounds before the re-start. After each round, all participants were informed about their own earnings.

In total, 224 students - 56 subjects per treatment - participated in the experiment. ${ }^{5}$ One session lasted for about 1.5 hours, and subjects earned about 12.64 Euros on average in addition to a show-up fee of 3 Euros. One round was randomly chosen to be relevant for the payoff both in part I and part II.

\footnotetext{
${ }^{5}$ We conducted four additional sessions to analyze two more treatments, which will be explained in section 4.
} 


\section{Results}

First, we present the mean contribution per individual in the different treatments. Figure 1 indicates that average contributions are similarly low in groups with at least one stranger in part I. In PPPP cooperation is significantly higher in part I than in all other treatments (pairwise comparison, Mann Whitney U-tests each $\mathrm{p}<0.001$ ).

Interestingly, participants change their contributions differently subsequent to the re-formation of groups from part I to part II. Former PPSS groups strongly and significantly increase their contribution subsequent to becoming a PPPP group in round 11 (Wilcoxon signed-rank test: $\mathrm{p}=0.001$ ); the same is true for SSSS groups (Wilcoxon signedrank test: $\mathrm{p}=0.006$ ), whereas individuals in the PPPP treatment decrease their contributions slightly from part I to part II (Wilcoxon signed-rank test: $\mathrm{p}=0.0196$ ). Most remarkably, we observe a considerable decrease in the PPPS treatment (Wilcoxon signed-rank test: $\mathrm{p}=0.006$ ).

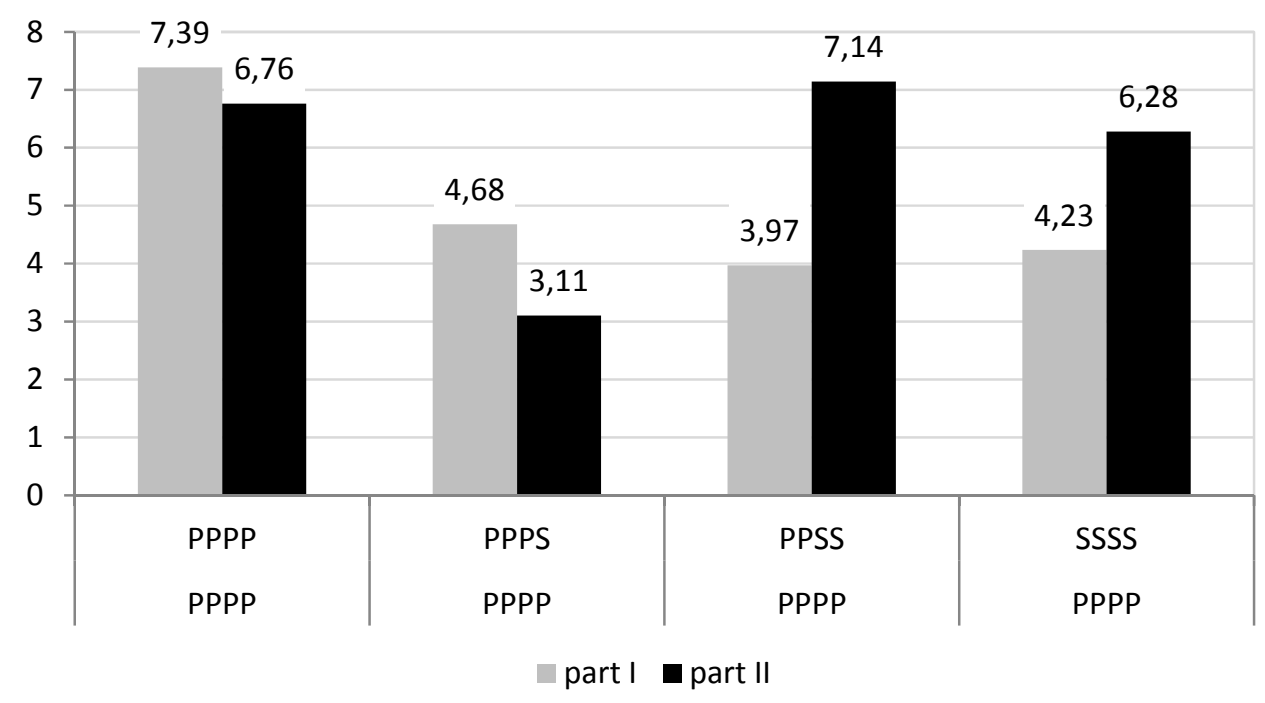

Figure 1: Mean individual contribution per treatment

The level of cooperation is similar in former PPPP, PPSS and SSSS settings in part II and is not different at a conventional significance level, whereas contributions of former PPPS groups are significantly lower than in all other treatments (pairwise comparison, Mann Whitney U-test, $\mathrm{p}<0.01$ each).

In order to shed light on the question of whether former partners contribute differently than former strangers after being converted into partners, we focus on our two treatments with blended groups in part I of the experiment in 
the following and we distinguish between the mean individual contributions dependent on their role in part I (Figure 2). In the PPPS/PPPP-treatment, former P in PPPS decrease their contribution considerably and significantly from part I to part II (Wilcoxon signed-rank test: $\mathrm{p}=0.008$ ), while former strangers slightly - but insignificantly - increase their contribution compared to part I. In contrast, former partners (Wilcoxon signed-rank test: $\mathrm{p}=0.047$ ) as well as former strangers ( $\mathrm{p}=0.013$ ) significantly increase their contributions in PPSS/PPPP groups. On average, there is no significant difference in contribution levels between former $\mathrm{P}$ and former $\mathrm{S}$ in either of the treatments PPPS or PPSS during part II.

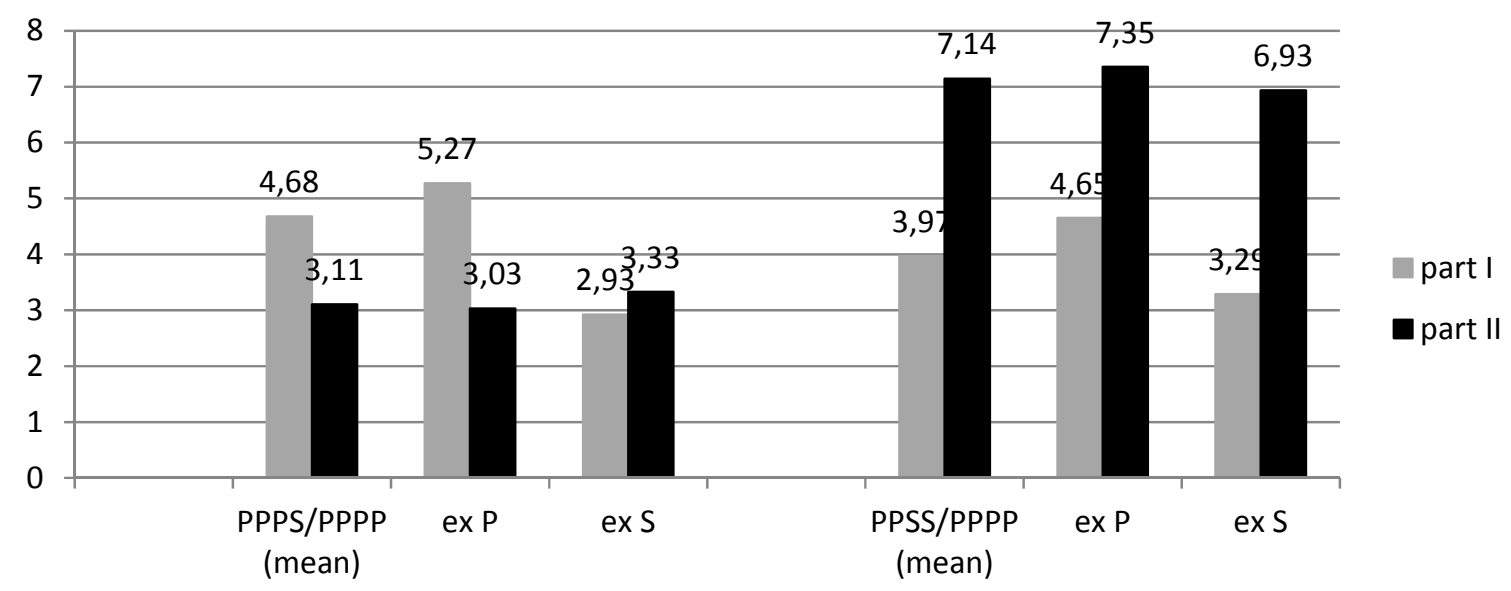

Figure 2: Mean individual contribution dependent on type in part I in blended groups

The descriptive findings already point in the direction of familiarity alone not being able to explain the contribution patterns that we observe. Familiarity in our setting here decreases with the number of strangers in the first part of the experiment. Thus, we have the highest degree of familiarity in the partners-only treatment PPPP/PPPP. As cooperation in part II is higher in PPSS/PPPP than in PPPS/PPPP familiarity cannot explain our results. In order to explore whether past group success and/or reciprocity explain part or whole contribution patterns after changes in group membership, we conduct a multivariate analysis. We run Tobit estimations on individual contributions in part II with robust standard errors clustered at the group level to check possible channels for differences in cooperation (see Table 2).

Familiarity is operationalized by the treatment effects: We compare the contribution of each type of player in each treatment to maximum familiarity as in PPPP/PPPP. As declining contribution patterns are frequently observed in repeated public good situations, we control for the round. Model (1) confirms our results from non-parametric testing, i.e., lower contributions in PPPS for both player types in part II. Hints of reciprocity are given by subjects' 
reactions towards previous contributions (particularly among partners) and a correlation of belief towards others and own contribution.

In model (2), we further control for the past cooperation experience of individuals by (a) the mean contribution of an individual's other group members and (b) the own mean contribution in part I. Hence, the positive coefficients for PPSS and SSSS confirm particular increases in contributions from part I to part II already illustrated by Figure 1 and 2 above. In contrast, there is no relative increase of contributions from part I to part II for S in PPPS compared to the PPPP treatment. Most remarkably, low contributions in part I in PPPS do not explain the even decreasing contributions of former P-type players in part II. Not surprisingly, beliefs about other group members' contributions in the present round reflect experiences of the past to some extent (Model 3). Given these beliefs, there are no considerable differences between present contributions in PPPP and both PPSS and SSSS. However, there are still significant negative coefficients in the PPPS treatment. This pattern holds for both type of players in the PPPS treatment even when controlling for the other group members' contribution in the previous round in model (4). Therefore, the willingness to cooperate seems to be fundamentally undermined in the PPPS treatment. This seems particularly relevant for the former P-type players who considerably decrease contributions in part II of the experiment compared to part I. 
Table 2: Tobit estimation results for round 11-20, dependent variable: individual contribution

\begin{tabular}{|c|c|c|c|c|c|c|c|c|}
\hline & (1) & & (2) & & (3) & & (4) & \\
\hline Round & $-1.855 * * *$ & $(0.114)$ & $-1.841^{* * *}$ & $(0.101)$ & $-0.653 * * *$ & $(0.067)$ & $-0.059 * * *$ & $(0.077)$ \\
\hline$\frac{\text { Past role }}{\text { (reference: } \mathrm{P} \text { in PPPP) }}$ & & & & & & & & \\
\hline $\mathrm{P}$ in PPPS & $-8.257 * * *$ & $(0.939)$ & $-3.114 * * *$ & $(0.890)$ & $-1.348 * *$ & $(0.523)$ & $-1.401 * * *$ & $(0.531)$ \\
\hline $\mathrm{S}$ in PPPS & $-7.826 * * *$ & (1.443) & -0.314 & (1.256) & $-2.081 * *$ & $(0.916)$ & $-2.027 * *$ & $(1.008)$ \\
\hline $\mathrm{P}$ in PPSS & 0.245 & (1.171) & $4.910^{* * *}$ & (1.066) & -0.606 & $(0.666)$ & -0.619 & $(0.696)$ \\
\hline$S$ in PPSS & 0.550 & (1.110) & $7.455^{* * * *}$ & (1.074) & $1.159 *$ & $(0.618)$ & 1.046 & $(0.637)$ \\
\hline $\mathrm{S}$ in SSSS & -0.937 & $(0.864)$ & $4.560^{* * *}$ & $(0.803)$ & -0.065 & $(0.524)$ & 0.034 & $(0.545)$ \\
\hline $\begin{array}{l}\text { Mean contribution of other } \\
\text { group members in part I }\end{array}$ & & & 0.006 & $(0.031)$ & $-0.214 * * *$ & $(0.022)$ & $-0.209 * * *$ & $(0.006)$ \\
\hline $\begin{array}{l}\text { Mean own contribution } \\
\text { in part I }\end{array}$ & & & $0.163^{* * *}$ & $(0.008)$ & $0.080^{* * *}$ & $(0.006)$ & $0.079 * * *$ & $(0.024)$ \\
\hline $\begin{array}{l}\text { Belief about other group members } \\
\text { contribution in present round }\end{array}$ & & & & & $0.468 * * *$ & $(0.012)$ & $0.428^{* *}$ & $(0.026)$ \\
\hline $\begin{array}{l}\text { Other members' contributions } \\
\text { in the previous round }\end{array}$ & & & & & & & $0.033^{*}$ & $(0.019)$ \\
\hline Constant & $32.479 * * *$ & $(1.825)$ & $20.016^{* * *}$ & $(1.764)$ & $3.194 * * *$ & (1.158) & 2.124 & $(1.341)$ \\
\hline Observations & 2,240 & & 2,240 & & 2,240 & & 2016 & \\
\hline $\mathrm{R}^{2}$ & 0.038 & & 0.098 & & 0.237 & & 0.241 & \\
\hline
\end{tabular}

Notes: Robust and clustered standard errors in parentheses. ${ }^{* *} \mathrm{p}<0.01,{ }^{* *} \mathrm{p}<0.05,{ }^{*} \mathrm{p}<0.1$. 
While reciprocity and the experience made in part I may help to explain cooperation after re-formation in three treatments, it is striking that we found one treatment (PPPS) in which neither familiarity nor behavior in part I seems to explain subsequent individual behavior. We will therefore scrutinize this treatment in the following compared to the other treatment with blended groups in part I.

When having a closer look at the contributions over time, we find that after the re-start, former S in PPPS start with contributions that are almost as high as the contributions of P and S in PPSS on average. For round 11, there is no significant difference in contributions between partners and strangers in PPSS and strangers in PPPS, but former partners in PPPS contribute significantly less than all other agents in PPPS and PPSS (all Mann-Whitney tests: $\mathrm{p}<0.088$ ). This is the case, although contributions patterns of partners do not differ between these treatments in part I of the experiment and are almost exactly equal in round 10 (see Figure A in the Appendix). However, after round 11 and possibly as former $\mathrm{S}$ become aware of the small contribution levels of former $\mathrm{P}$ in PPPS, also former $\mathrm{S}$ decrease their contributions and converge to the level of former P (see Figure 3). Contributions are on a somewhat higher level over all rounds in the PPSS treatment for both former S- and former P-type players.

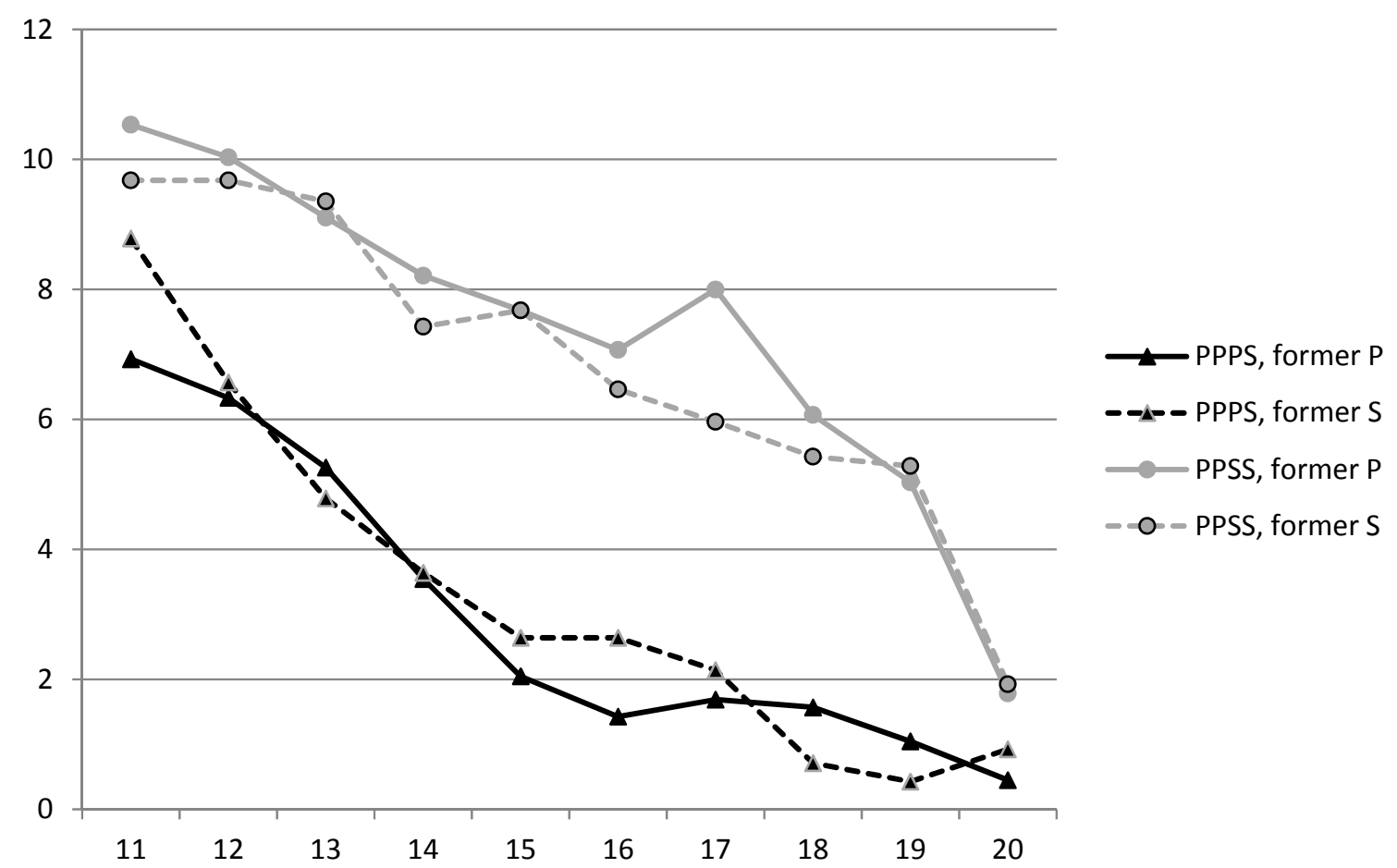

Figure 3: Contributions by treatment and previous type of player over rounds in part II 
The low contributions of former P in PPPS come along with respective low beliefs towards their group members' contributions. On average, P expect their fellow group member P to contribute a mean of 3.6 in part II (compared to 5.640 in part I, $\mathrm{p}<0.001$ ) while they do not increase their beliefs about the fourth member, i.e. the stranger who is converted into a partner from part I to part II (part I=3.557, part II=3.769, $\mathrm{p}=0.941$ ). Contrary to that, former $\mathrm{P}$ in PPSS significantly increase their expectations towards former P (part $\mathrm{I}=6.600$, part $\mathrm{II}=8.232, \mathrm{p}<0.001$ ) and newcomers, i.e. the strangers who are converted into partners (part $I=4.466$, part $I I=7.534, p<0.001$ ). Figure 4 displays the course of average beliefs for each type of player in the blended groups per round. Having been assigned to a new group, participants may adapt their beliefs based on the new situation and prior experiences. Thus, initial beliefs may indicate whether the new group composition is perceived as "good news" or "bad news".

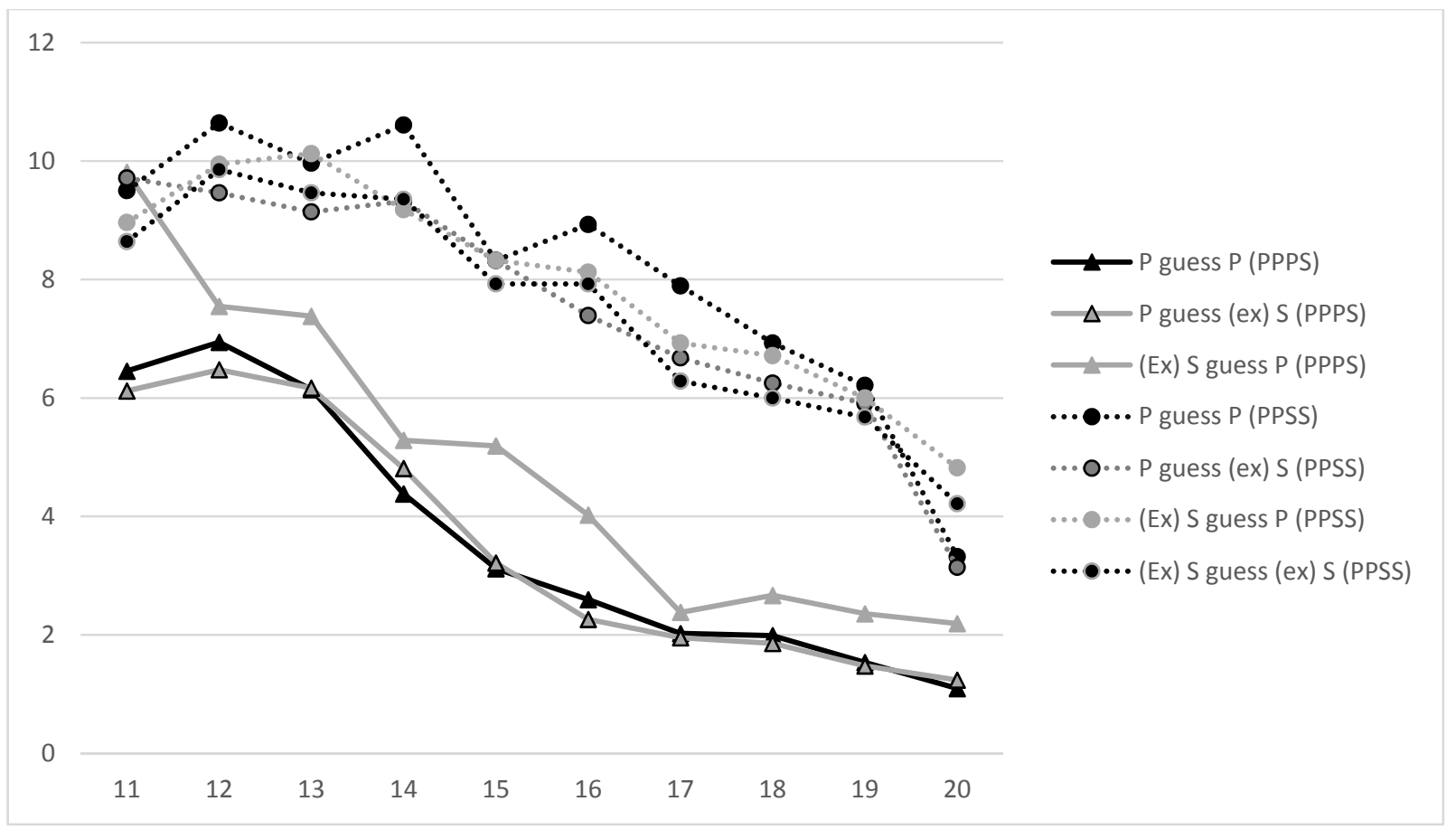

Figure 4: Beliefs in PPPS/PPPP and PPSS/PPPP over rounds in part $\mathrm{II}^{6}$

Strikingly, former S in the PPPS/PPPP setting expect contributions to be high in the first round after the re-start and they expect the same level of contributions as all other individuals in the PPSS/PPPP setting. The former partners in the PPPS/PPPP setting, however, expect low contributions from each of their other fellow partners as well as from the newcomer in the group. The gap between expectations of contributions in round 11 is at least three points between the expectations of oldtimers in PPSS and newcomers in both settings on the one hand and former partners in PPPS on the other hand. After round 11, former strangers in PPPS adapt to the situation and also lower their

\footnotetext{
${ }^{6}$ See, for all beliefs over the course of the 20 rounds, Appendix 2, Figure B.
} 
beliefs. Therefore, this picture suggests that especially former partners in PPPS are initially responsible for the low contributions in part II.

In order to understand the behavior of former partners in the PPPS/PPPP treatment in more detail, we focus on subjects who are partners in part I in the following. We therefore re-estimate the Tobit model of Table 2 now focusing on the partners (see Table 3). Model 1 corresponds to the final model 4 of table 2 and confirms the lower contributions in the PPPS treatments even when controlling for contributions in part I, present beliefs and contributions in the previous round. Additionally, to the variables used in model 1, we analyze the mean belief about partners' contributions in the first part of the experiment as an anchor and the degree of the impact of this variable on current contribution as an indicator for reciprocity among partners. The intuition is the following: If individuals think that their familiar group members (partners) have cooperated well - reflected by their beliefs in the past - they might feel the desire to reciprocate positively now.

However, Model 2 shows that the mean belief about partners' contributions in the first part of the experiment is not significantly related to current contributions. Models 3 to 5 provide separate estimations by treatment. Interestingly, the relation between the mean belief about partners' contribution in part I and own contribution differs dramatically across treatments (corresponding estimations with interaction terms - not reported - coincide with this finding). Obviously, there is a positive reciprocal behavior in PPPP/PPPP and PPSS/PPPP. Subjects react with higher contributions in part II the higher their beliefs are about the behavior of their partner group mates of the past. The opposite is true for PPPS/PPPP. Whereas low group contributions in PPSS may be easily ascribed to the two former $S$ players from a partner perspective, this might be much more difficult, when there has been only one $\mathrm{S}$. The hint at negative reciprocity may be explained by partners being disappointed about the contributions in part I and now reacting negatively with low contributions the higher their expectations in part I were.

This result is noteworthy as it persists even after controlling for a group's past performance: As hypothesized, past cooperation has an effect on contributions in a changed group situation and is probably the most important determinant for individual effort. However, even after controlling for past contribution levels, PPPS groups fail to integrate a new permanent group member. 


\begin{tabular}{|c|c|c|c|c|c|c|c|c|c|c|}
\hline \multirow[b]{2}{*}{ Round } & \multicolumn{2}{|c|}{ (1) } & \multicolumn{2}{|c|}{ (2) } & \multicolumn{2}{|c|}{$\begin{array}{c}\text { (3) } \\
\text { PPPP/PPPP }\end{array}$} & \multicolumn{2}{|c|}{$\begin{array}{c}\text { (4) } \\
\text { PPPS/PPPP }\end{array}$} & \multicolumn{2}{|c|}{$\begin{array}{c}\text { (5) } \\
\text { PPSS/PPPP }\end{array}$} \\
\hline & $-0.588 * * *$ & $(0.106)$ & $-0.592 * * *$ & $(0.106)$ & $-0.756 * * *$ & $(0.170)$ & $-0.213^{*}$ & $(0.110)$ & $-0.565 * *$ & $(0.258)$ \\
\hline \multicolumn{11}{|l|}{ Past role (reference: $\mathrm{P}$ in PPPP) } \\
\hline $\mathrm{P}$ in PPPS & $-1.334 * *$ & $(0.544)$ & $-1.301 * *$ & $(0.552)$ & & & & & & \\
\hline $\mathrm{P}$ in PPSS & -0.904 & $(0.730)$ & -0.632 & $(0.768)$ & & & & & & \\
\hline $\begin{array}{l}\text { Contribution of other group members } \\
\text { in part I }\end{array}$ & $-0.247 * * *$ & $(0.031)$ & $-0.214^{* * *}$ & $(0.041)$ & $-0.162 * * *$ & $(0.055)$ & $-0.136 * * *$ & $(0.050)$ & -0.031 & $(0.199)$ \\
\hline Own contribution in part I & $0.877 * * *$ & $(0.085)$ & $0.938 * * *$ & $(0.111)$ & $1.520 * * *$ & $(0.172)$ & $0.335 * * *$ & $(0.084)$ & $1.441^{* * *}$ & $(0.377)$ \\
\hline $\begin{array}{l}\text { Belief about other group members' } \\
\text { contribution in current round }\end{array}$ & $0.426^{* * *}$ & $(0.035)$ & $0.433^{* * *}$ & $(0.036)$ & $0.378 * * *$ & $(0.053)$ & $0.340 * * *$ & $(0.043)$ & $0.835^{* * *}$ & $(0.116)$ \\
\hline $\begin{array}{l}\text { Other members' contributions in the } \\
\text { previous round }\end{array}$ & $0.048 *$ & $(0.025)$ & 0.042 & $(0.027)$ & $0.094 * * *$ & $(0.036)$ & $0.065 *$ & $(0.034)$ & $-0.240 * * *$ & $(0.075)$ \\
\hline $\begin{array}{l}\text { Mean belief about the partners' } \\
\text { contribution in part I }\end{array}$ & & & -0.178 & $(0.156)$ & $0.999 * * *$ & $(0.246)$ & $-0.216^{* * *}$ & $(0.052)$ & $1.647 * * *$ & $(0.368)$ \\
\hline Constant & 1.873 & $(1.703)$ & 2.243 & $(1.748)$ & $5.701 * *$ & $(2.641)$ & -2.481 & $(1.840)$ & -1.363 & $(4.473)$ \\
\hline Observations & \multicolumn{2}{|c|}{1,134} & \multirow{2}{*}{\multicolumn{2}{|c|}{1,134}} & \multicolumn{2}{|c|}{504} & \multirow{2}{*}{\multicolumn{2}{|c|}{$\begin{array}{c}378 \\
0304\end{array}$}} & \multicolumn{2}{|c|}{252} \\
\hline Pseudo R & \multicolumn{2}{|c|}{0.265} & & & \multicolumn{2}{|c|}{0.275} & & 0.304 & \multicolumn{2}{|c|}{0.248} \\
\hline
\end{tabular}

Table 3: Tobit estimation results for rounds 11-20 for former partner, dependent variable: individual contribution 
An Analysis of the "Bad Apple"-Phenomenon - Additional Treatments

Interestingly, we find that in the PPPS groups cooperation is much lower after conversion into a group with partners only. And, their failure to cooperate in part II cannot be completely explained by their precedent experiences, reciprocity or familiarity. Our finding is strikingly reminiscent of the bad apple-phenomenon (Felps et al. 2006, Kerr et al. 2009, de Oliveira et al. 2014). The bad apple phenomenon is described as a situation of low contributions of all group members, where all group members expect to have one bad apple - i.e. one free rider - in the group. The main reasoning is that the group members' true or false expectation about one group member's uncooperativeness leads to low contribution within the whole group. In the psychological literature, this blaming of one group member is known as an ultimate attribution error (Pettigrew 1979).

We therefore want to explore the behavior in this specific situation of group re-formation in more detail by conducting additional treatments with the same re-formation of the group structure, but with different information about the newcomer in order to vary the level of information and to explore whether information can antagonize the bad apple blaming.

The lower contributions are reflected by the expectations of the former P in PPPS as they significantly decline in their beliefs not only towards the newcomer, i.e., (the former) stranger, but also towards other oldtimers, i.e., partners. This finding is in line with McCarter and Sheremeta (2013) who also show that newcomers do not only hazard a group's effectiveness by the mere addition of a new member, but also by casting doubt among oldtimers, which may lead to a breakdown of contributions.

Past research on newcomer integration reveals that a newcomer's reputation is crucial for her integration into existing groups: Information about her past will significantly impact subsequent performance of the group (McCarter and Sheremeta 2013, Moreland and Levine 2002). In coordination settings, where trust plays a crucial role for coordination, Moreland and Levine (2002) show that coordination improves if oldtimers receive information about newcomers' past effort. Likewise, McCarter and Sheremata (2013) show that coordination further improves, if not only oldtimers receive information about the newcomer's past performance, but also if newcomers receive information about the oldtimers' past contributions. Both papers rely on trust as the coordination enabling mechanism which is improved the less information asymmetry exists.

In contrast to coordination settings, however, the individual effort is not observable in a cooperation framework per definition. In our research setting, the question arises of whether other signals given about the newcomer can also lead to an improvement in effort levels. In most organizational settings, information about past effort might not 
always be available, but information about the former role of the newcomer can easily be given. We distinguish three possible signals:

(1) In our hitherto PPPS/PPPP-treatment, the newcomer can be anyone and it is likely that the oldtimers will have already played with the newcomer in the past when she was a temporary group member. In this case, cooperation failures in the past might be attributed to the newcomer, because oldtimers might think that she had already caused low cooperation levels in the past.

(2) The newcomer can be someone who was a temporary group member in other groups in the past. In this case, the oldtimers are assured that they have never met the newcomer in the past so that the group's past performance had not suffered from this newcomer's past contributions.

(3) The newcomer can be someone who had the role of a permanent group member in another group in the past: In this case, the oldtimers know that the group's past performance had not been influenced by this newcomer's past contributions, and that the newcomer had played a similar role as themselves and had probably experienced some cooperation.

We expect that all three signals will lead to different contribution levels in part II as the signals fundamentally differ: Newcomer integration might be easier, the more alike the newcomer and the oldtimers are (case 3) and is easier if the newcomer is a real newcomer to the group (case 2) compared to a situation when the newcomer might have been a cause of low contributions in the past (case 1).

We model the signals (2) and (3) by conducting two additional treatments using two variations of our PPPS/PPPP setting; in the following we denote our PPPS/PPPP setting as control treatment because it represents signal (1). In the first additional treatment, we give the players the (true) information before round 11 that the new group member has been a player of type S (stranger) in rounds 1 to 10 , but has never played with this distinctive group before (SInfo). The former partners have no reason to attribute previous cooperation problems in round 1 to 10 to the newcomer as the S player is completely new to the group and no interaction has taken place before. Second, we match the three partners of PPPS groups of the first 10 rounds with another former player of type P (partner) of a different group and give this information to all subjects ( $P$-Info). The former three group members may expect the new member to have learned to cooperate as they themselves did so that cooperation may also emerge in this treatment. However, they had never met before. Thus, behavior stemming from past interaction with the new group member in part I is also excluded here.

The situation is the same for subjects across these three treatments in rounds 1 to 10 , as expected contributions do not differ significantly in part I (see Figure 5). However, the additional information is a key driver of contributions in part II of the experiment. Giving the information that a new - former stranger - player is joining the group leads to a considerably higher degree of cooperation than in the Control treatment (Mann-Whitney- test: $\mathrm{p}=0.0003$ ). Contributions in the P-Info treatment are even higher with an average of 9.32 (Mann-Whitney-test compared to Control: $\mathrm{p}<0.00001)$ and compared to S-Info $(\mathrm{p}=0.010)$. This behavior results in a moderate increase in 
contributions from part I to part II in the S-Info case from 5.36 to 6.64 (Wilcoxon test, $\mathrm{p}=0.053$ ) and in a huge increase in the P-Info treatment $(\mathrm{p}<0.001)$, whereas contributions decrease in the Control treatment as mentioned above.

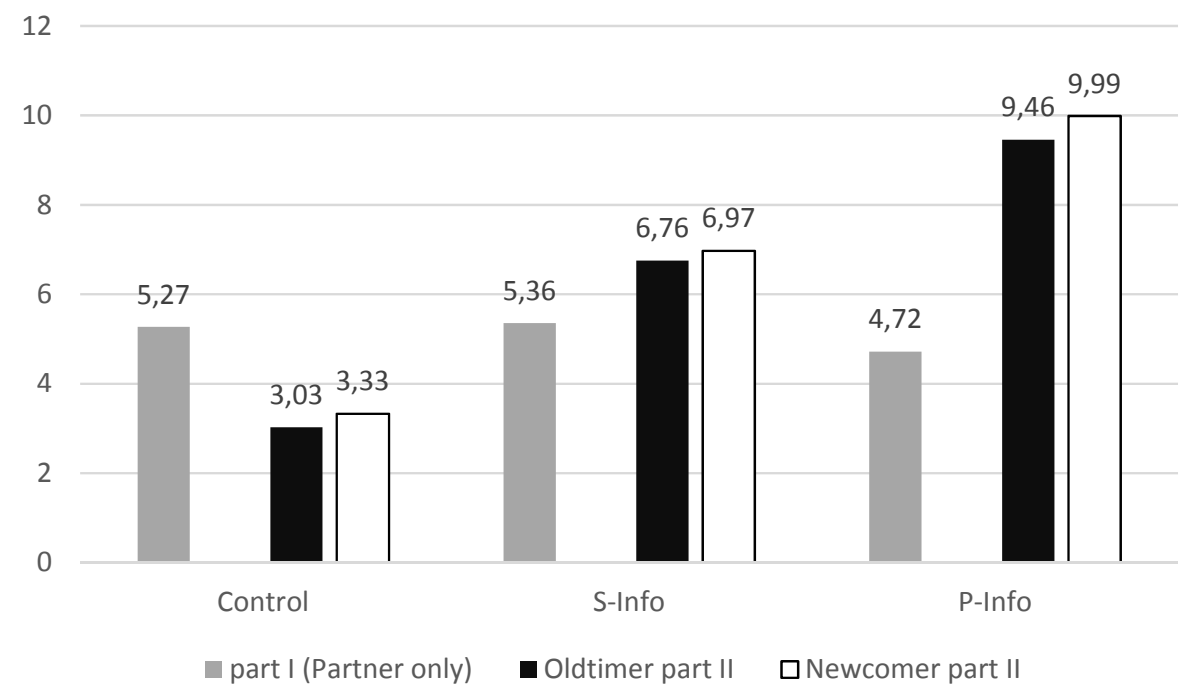

Figure 5: Contributions in additional treatments

Average contributions do not differ considerably between oldtimers and group newcomers in all three treatments in part II. The results are in line with respective beliefs in each treatment. Figure 6 displays the mean beliefs of oldtimers towards other oldtimers and the newcomer in all three treatments. There are no significant differences between beliefs towards oldtimers and newcomers within one treatment, while all differences between treatments are significant (each pairwise test, $\mathrm{p}<0.01$ ). 


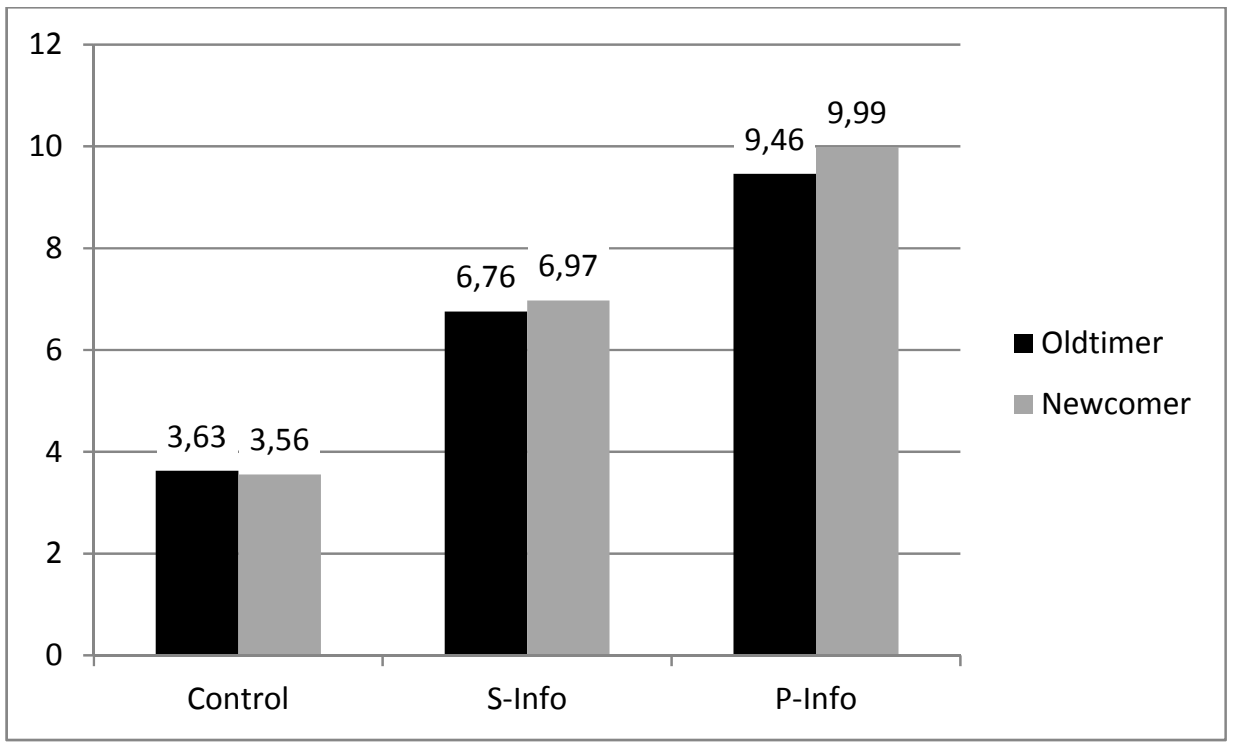

Figure 6: Beliefs of former $P$ towards oldtimers and newcomers in part II

(1)

(2)

(3)

\begin{tabular}{|c|c|c|c|c|c|c|}
\hline \multirow[b]{2}{*}{ Round } & \multicolumn{2}{|c|}{ Control } & \multicolumn{2}{|c|}{ S-Info } & \multicolumn{2}{|c|}{ P-Info } \\
\hline & $-0.213^{*}$ & $(0.110)$ & 0.215 & $(0.370)$ & -0.106 & $(0.327)$ \\
\hline $\begin{array}{l}\text { Contribution of other group members in } \\
\text { part I }\end{array}$ & $-0.136 * * *$ & $(0.050)$ & $0.568 * * *$ & $(0.128)$ & $0.371^{* * *}$ & $(0.121)$ \\
\hline Own contribution in part I & $0.335^{* * *}$ & $(0.084)$ & $0.950^{*}$ & $(0.499)$ & $1.163^{* * *}$ & $(0.387)$ \\
\hline $\begin{array}{l}\text { Belief about other group members' } \\
\text { contribution in each round }\end{array}$ & $0.340^{* * *}$ & $(0.043)$ & $1.818^{* * *}$ & $(0.313)$ & $1.565^{* * *}$ & $(0.436)$ \\
\hline $\begin{array}{l}\text { Other members' contributions in the } \\
\text { previous round }\end{array}$ & $0.065^{*}$ & $(0.034)$ & $-0.366 * * *$ & $(0.113)$ & $-0.265 * *$ & $(0.110)$ \\
\hline $\begin{array}{l}\text { Mean belief about the partners' } \\
\text { contribution in part I }\end{array}$ & $-0.216^{* * *}$ & $(0.052)$ & $1.977^{* * *}$ & $(0.811)$ & $1.428 * * *$ & $(0.454)$ \\
\hline Constant & -2.481 & $(1.840)$ & -4.142 & $(5.828)$ & -6.784 & $(5.657)$ \\
\hline Observations & \multicolumn{2}{|c|}{378} & \multirow{2}{*}{\multicolumn{2}{|c|}{162}} & \multicolumn{2}{|c|}{162} \\
\hline Pseudo-R² & \multicolumn{2}{|c|}{0.304} & & 0.405 & \multicolumn{2}{|c|}{0.316} \\
\hline
\end{tabular}

Robust standard errors in parentheses

${ }^{* * *} \mathrm{p}<0.01,{ }^{* *} \mathrm{p}<0.05, * \mathrm{p}<0.1$

Table 4: Tobit estimation results for rounds 11-20 for former partner (additional treatments) 
In line with Table 3 (models 3 to 5) we also explore the determinants of individual cooperation by treatments with Tobit estimations. Model 1 of Table 4 repeats the estimation of our control treatment PPPS/PPPP of Table 3. The oldtimers' higher contributions in S-Info and P-Info come along with a positive relation of mean belief about the partners' contributions in part I and current own contributions. We know this relation already from the other treatments PPPP and PPSS. It is therefore not necessarily only the specific former group composition PPPS that matters, but rather the specific information structure together with some signals, as described above, that drives behavior.

\section{Summary and Discussion}

We contribute to the literature by analyzing the impact of changing group membership on cooperative behavior in public good games. Based on a laboratory experiment, we particularly investigate whether the conversion of temporary into permanent group members improves productivity. Groups are not equally receptive to new group members and modified group conditions: In the setting with permanent members only, which serves as our baseline setting, contributions are roughly the same in both parts of the experiment. Compared to this partner treatment with permanent members only cooperation is much lower in the first part if the group partly or solely consists of temporary members (strangers). However, after converting temporary members into permanent members, cooperation is about the same as in the baseline setting if there are at least two temporary members in part I.

Interestingly, in groups with just one temporary member in part I cooperation is significantly lower than in all other settings after conversion of the temporary members into permanent ones. Taking a closer look at subjects' beliefs towards others' behavior shows that partners in PPPS do not expect former strangers or other partners to contribute more in part II, unlike the case in PPSS. Our regression analysis shows that we cannot explain lower contributions in PPPS with differences in previous contributions in part I of the experiment or by current beliefs. ${ }^{7}$

To gain a better understanding of this puzzling result in PPPS we conduct additional treatments with just one temporary member in the first part of the experiment. In the first of our two additional treatments, we inform participants at the beginning of the second part that a permanent member will be added to the group who had been a temporary member in other (foreign) groups before; thus, we assure them that no interaction with this subject has ever taken place before. Cooperation in the second part turns out to be significantly higher than in our control setting PPPS from above, i.e., if interaction with former temporary members has potentially taken place. In our second additional treatment participants are informed that the newly added member of the group has been a permanent

\footnotetext{
${ }^{7}$ Note that recent work has shown that participants tend to respond more strongly to negative deviations from their expectations than to positive ones (see de Oliveira et al. 2009). Moreover, McCarter \& Sheremata (2013) show in coordination games that poor performance among oldtimers may induce more distrust than towards newcomers.
} 
member in other groups before. This considerably enhances cooperation in the second part of our experiment and illustrates quite impressively the additional importance of the type of group member.

How can we now explain the different behavior in PPPS groups after conversion into an all-partners group? In treatments with at least two strangers in the first part results are in line with what we would have expected based on previous findings. Groups manage cooperation quite well after being converted into a group with permanent members only and achieve cooperation as highly as in a setting with only partners at all times. Interacting with permanent group members may more easily induce trust among subjects within a group enabling them to cooperate on a higher level. Other studies have shown that participants try to match behavior of others in public good games, which is in line with conditional cooperation (e.g. Croson 2007). Subjects obviously anticipate that cooperation is easier for permanent members, which is reflected by their beliefs. So, informing participants that all temporary group members are now permanent members seems to be perceived as "good news" in settings with at least two temporary members and effectively enhances cooperation.

If there is only one temporary group member this information could obviously not improve the situation. Instead, former permanent group members even decrease their contributions compared to the first part. They do not expect their former partners or the former stranger to increase cooperation levels, unlike the case in other treatments; thus the information about the conversion of the stranger into a permanent member is not perceived as "good news". One might conclude that they trust oldtimers as well as newcomers less than it is the case in other settings. Thus, low cooperation levels in the second part are not initially induced by the former strangers, but obviously by former partners. The results from our additional treatment S-Info indicate that partners perceive the one stranger in their group as a "bad apple spoiling the bunch" and mistakenly attribute the reason for cooperation problems in part I to the specific subject instead of attributing the low cooperation levels to the exogenously given group composition. ${ }^{8}$ This is in line with the findings on the ultimate attribution error according to which negative outgroup behavior is falsely attributed to the individuals' personalities and not to circumstances (Hewstone 1990). The one stranger may be perceived as an outgroup participant in PPPS. If we assign a completely new subject to the group in the second part who had been a stranger before, cooperation levels are considerably increased if the newcomer is integrated as a permanent member. Thus, partners seem to attribute prior cooperation failure to the decisions of the specific strangers they have interacted with and not to the assigned role, although they also understand that former partners may more easily cooperate, as indicated by our further treatment $P$-Info. In addition, they seem to be disappointed by the other partners' behavior in part. They may have expected that with just one stranger the partners could have compensated for lower contribution levels of the one bad apple and achieved a higher cooperation level. As their

\footnotetext{
${ }^{8}$ For an economic approach as to why one „bad apple may spoil the barrel” see Myatt \& Wallace (2008); for a review and a conceptual approach, see Felps et al. (2006).
} 
expectations are not fulfilled subjects may then decrease their contributions and expectations especially if conditional cooperation is relevant.

The reason for a different behavior in PPSS and SSSS compared to the PPPS treatment may be that the fact that having two or more strangers in the group is not as salient as in the PPPS treatment with only one bad apple that literally stands out in the group. ${ }^{9}$ Thus, in PPSS strangers might not be stigmatized as outgroup participants, since they represent half of the group. Moreover, in PPSS partners do not seem to be disappointed by the other partner in part I and even increase beliefs towards the former partner in part II. Instead, there are indicators for positive reciprocity in part II regarding behavior in part I. Thus, if there is only one member perceived as a bad apple, participants might falsely assume that lower contribution levels could easily be compensated in such a setting that is only marginally different from a homogenous group with partners only. Realizing that this is not feasible, they lower their beliefs and own contribution levels. In groups with a more balanced fraction of different types this (false) assumption may not initially drive participants’ decisions.

Our results give some insight into cooperation problems of groups dependent on group membership. We show that a specific group composition may have an impact on subsequent behavior, which cannot completely be explained by the actual decisions in a previous setting. Although recent work has shown that "one bad apple may not (always) spoil the bunch", since cooperation marginally decreases with the number of lower contributors (de Oliveira et al. 2014), our results demonstrate that a setting with one bad apple may affect subsequent performance because of attribution errors made by others in the group. Whenever work groups are fluid and individual workers are newly assigned to a team such effects may well explain why some groups achieve high cooperation levels afterwards and others fail even if conditions have improved.

\footnotetext{
${ }^{9}$ For an analysis of the impact of the saliency of group membership, see Charness et al. (2007).
} 


\section{References}

Ahn, T. K., Ostrom, E., Schmidt, D., Shupp, R., \& Walker, J. (2001). Cooperation in PD games: Fear, greed, and history of play. Public Choice 106(1-2), 137-155

Alchian AA, Demsetz H (1972) Production, information costs, and economic organization. American Economic Review 62(5):777-795.

Andreoni J, Croson R (2008) Partners versus strangers: Random rematching in public goods experiments. Plott CR, Smith VL, eds. Handbook of Experimental Economics Results: Vol. 1, Chap. 82 (Elsevier, Amsterdam), 776783.

Angelova V, Güth W, Kocher MG (2012) Co-employment of permanently and temporarily employed agents. Labour Economics 19(1):48-58.

Berninghaus S, Bleich S, Güth W (2013) The consequences of (de)regulation on employment duration and efficiency: An experimental study. Economic Inquiry 51(1):1050-1065.

Charness G, Cobo-Reyes R, Jiménez N (2014) Identities, selection, and contributions in a public-goods game. Games and Economic Behavior 87:322-338.

Charness G, Rigotti L, Rustichini A (2007) Individual behavior and group membership. American Economic Review 97(4):1340-1352.

Chaudhuri A (2011) Sustaining cooperation in laboratory public goods experiments: A selective survey of the literature. Experimental Economics 14(1):47-83.

Che Y-K, Yoo S-W (2001) Optimal incentives for teams. American Economics Review 91(3):525-541.

Choi H-S, Thompson L (2005) Old wine in a new bottle: Impact of membership change on group creativity. Organizational Behavior and Human Decision Processes 98(2):121-132.

Croson RTA (2007) Theories of commitment, altruism and reciprocity: Evidence from linear public goods game. Economic Inquiry 45(2):199-216.

Fehr E, Gächter S (2000) Cooperation and punishment in public goods experiments. American Economic Review 90(4):980-994.

Felps W, Mitchell TR, Byington E (2006) How, when, and why bad apples spoil the barrel: Negative group members and dysfunctional groups. Research in Organizational Behavior 27:175-222.

Feri, F, Irlenbusch B, Sutter M (2010) Efficiency Gains from Team-Based Coordination-Large-Scale Experimental Evidence. American Economic Review 100(4): 1892-1912. 
Fischbacher U (2007) z-Tree: Zurich toolbox for ready-made economic experiments. Experimental Economics 10(2):171-178.

Goodman PS, Leyden DP (1991) Familiarity and group productivity. Journal of Applied Psychology 76(4):578.

Gneezy U, Leibbrandt A, List JA (2015) Ode to the Sea: Workplace Organization and Norms of Cooperation. The Economic Journal. doi: 10.1111/ecoj.12209.

Greiner B (2004) The Online Recruitment System ORSEE 2.0 - A Guide for the Organization of Experiments in Economics. Papers on Strategic Interaction 2003-10, Max Planck Institute of Economics, Strategic Interaction Group.

Grund C, Harbring C, Thommes K (2015) Cooperation in diverse teams: The role of temporary group membership. Economics Letters 134:41-44.

Gürerk Ö, Irlenbusch I, Rockenbach B. (2014) On Cooperation in Open Communities. Journal of Public Economics 120: $220-230$.

Haas MR (2006) Knowledge gathering, team capabilities, and project performance in challenging work environments. Management Science 52(8):1170-1184.

Hewstone M (1990) The 'ultimate attribution error'? A review of the literature on intergroup causal attribution. European Journal of Social Psychology 20(4):311-335.

Hinds PJ, Carley KM, Krackhardt D, Wholey D (2000) Choosing work group members: Balancing similarity, competence, and familiarity. Organizational Behavior and Human Decision 81(2):226-251.

Holmström B (1982) Moral Hazard in teams. Bell Journal of Economics 13(2):324-340.

Huckman RS, Staats BR, Upton DM (2009) Team familiarity, role experience, and performance: Evidence from Indian software services. Management Science 55(1):85-100.

Ilgen DR, Hollenbeck JR, Johnson M, Jundt D (2005) Teams in organizations: From I-P-O models to IMOI models. Annual Review of Psychology 56:517-543.

Joshi A, Roh H (2009) The role of context in work team diversity research: A meta-analytic review. Academy of Management Journal 52(3):599-627.

Kalleberg A (2000) Nonstandard employment relations: Part-time, temporary and contract work. Annual Review of Sociology 2000:341-365.

Kendal E, Lazear EP (1992) Peer pressure and partnership. Journal of Political Economy 100(4):801-817.

Kerr NL, Rumble AC, Park ES, Ouwerkerk JW, Parks CD, Gallucci M, van Lange PA (2009) "How many bad apples does it take to spoil the whole barrel?”: Social exclusion and toleration for bad apples. Journal of Experimental Social Psychology 45(4):603-613. 
Keser C, van Winden F (2000) Conditional cooperation and voluntary contributions to public goods. The Scandinavian Journal of Economics 102:23-39.

Kozlowski SWJ, Bell BS (2003) Work groups and teams in organizations. Borman WC, Ilgen DR, Klimoski RJ, eds. Handbook of Psychology: Vol. 12 (Wiley-Blackwell, New York), 333-375.

Kozlowski SWJ, Ilgen DR (2006) Enhancing the effectiveness of work groups and teams. Psychological Science 7:77-124.

Lemieux-Charles L, McGuire WL (2006) What do we know about health care team effectiveness? A review of the literature. Medical Care Research and Review 63(3):263-300.

Littlepage G, Robison W, Reddington K (1997) Effects of task experience and group experience on group performance, member ability, and recognition of expertise. Organizational Behavior and Human Decision Processes 69(2):133-147.

Masclet D, Noussair D, Tucker S, Villeval MC (2003) Monetary and Non-Monetary Punishment in the Voluntary Contributions Mechanism. American Economic Review, 93 (1): 366-380.

Mathieu J, Maynard MT, Rapp T, Gilson L (2008) Team effectiveness 1997-2007: A review of recent advancements and a glimpse into the future. Journal of Management 34:410-476.

Mathieu JE, Tannenbaum SI, Donsbach JS, Alliger GM (2013) Achieving optimal team composition for success. Salas E, ed. Developing and enhancing high-performance teams: Evidence-based practices and advice (Jossey-Bass, San Francisco), 520-551.

Mathieu JE, Tannenbaum SI, Donsbach JS, Alliger GM (2014). A review and integration of team composition models moving toward a dynamic and temporal framework. Journal of Management 40(1):130-160.

Maurer I (2010) How to build trust in inter-organizational projects: The impact of project staffing and project rewards on the formation of trust, knowledge acquisition and product innovation. International Journal of Project Management 28(7):629-637.

McCarter MW, Sheremeta RM (2013) You can't put old wine in new bottles: The effect of newcomers on coordination in groups. Public Library of Science ONE 8(1):e55058.

Moreland LM, Levine JM (2002) Socialization and trust in work groups. Group Processes and Intergroup Relations 5(3):185-201.

Myatt DP, Wallace C (2008) When does one bad apple spoil the barrel? An evolutionary analysis of collective action. The Review of Economic Studies 75(2):499-527. 
Nalbantian HR., Schotter A (1997) Productivity under group incentives: An experimental study. The American Economic Review 87(3):314-341.

de Oliveira, A. C., Croson, R. T., \& Eckel, C. (2014). One bad apple? Heterogeneity and information in public good provision. Experimental Economics, 1-20.

Palfrey TR, Prisbrey JE (1996) Altuism, reputation and noise in linear public goods experiments. Journal of Public Economics 61(3):409-427.

Pettigrew TF (1979) The ultimate attribution error: Extending Allport's cognitive analysis of prejudice. Personality and Social Psychology Bulletin 5(4):461-476.

Rink FA, Ellemers N (2009) Temporary versus permanent group membership: How the future prospects of newcomers affect newcomer acceptance and newcomer influence. Personality and Social Psychology Bulletin 35(6):764-775.

Rink F, Kane AA, Ellemers N, van der Vegt G (2013) Team receptivity to newcomers: Five decades of evidence and future research themes. The Academy of Management Annals 7(1):247-293.

Sheremeta RM (2013) Overbidding and heterogeneous behavior in contest experiments. Journal of Economic Surveys 27(3):491-514.

Tajfel H, Turner JC (1979) An integrative theory of intergroup conflict. Austin WG, Worchel S, eds. The social psychology of intergroup relations, Chap. 3 (Brooks/ Cole, Monterey), 33-47.

Xyrichis A, Lowton K (2008) What fosters or prevents interprofessional teamworking in primary and community care? A literature review. International Journal of Nursing Studies 45(1):140-153. 


\section{Appendix I}

\section{Experimental Instructions (originally in German)}

Welcome and thank you for participating in this experiment. If you read the following instructions carefully, you can, depending on your decisions, earn a considerable amount of money. It is therefore very important that you read these instructions with care.

The instructions which we have distributed to you are solely for your private information. It is prohibited to communicate with the other participants during the experiment. Please make sure that you switched off your mobile devices. Should you have any questions, please ask us. If you violate this rule, we shall have to exclude you from the experiment and from all payments. During the experiment, we will not speak of Euros but rather of points. During the experiment your entire earnings will be calculated in ECU (Experimental Currency Units). At the end of the experiment the total amount of ECUs you have earned will be converted to Euros at the following rate:

\section{$1 \mathrm{ECU}=0.15 €$}

Your earning plus a show-up fee of 3 Euros will be paid cash to you after the experiment.

Nobody will learn about your earnings or your decisions. Please do also not discuss your decisions with other participants after the experiment.

\section{The decision situation}

You will learn later on how the experiment will be conducted. We first introduce you to the basic decision situation. At the end of the description of the decision situation, you will find control questions that will help you to gain an understanding of the decision situation.

You will be a member of a group of 4 people. Each member has to decide on the division of 20 ECUs. You can put these 20 ECUs on a private account or you can invest them fully or partially into a project. Each ECU you do not invest into the project will automatically be transferred to your private account.

\section{Your income from the private account}

For each ECU you put on your private account you will earn exactly one point. For example, if you put twenty ECUs on your private account (which implies that you do not invest anything into the project) you will earn exactly twenty ECUs from the private account. If you put 6 ECUs into the private account, you will receive an income of 6 ECUs from the private account. Nobody except you earns anything from your private account.

\section{Your income from the project}

From the ECU amount you invest into the project each group member will get the same payoff. Of course, you will also get a payoff from the ECUs the other group members invest into the project. Each ECU that is invested into the project will be multiplied by 1.6 and be equally distributed among all members of a group. That means that for each ECU invested in the project every member earns 0.4 ECUs, no matter which member of the group invested the ECU. For each group member the income from the project will be determined as follows:

Income from the project $=$ sum of contributions to the project $\mathrm{x} 0.4$

For example, if the sum of all contributions on the project is 60 ECUs, then you and all other group members will get a payoff of $60 \times 0.4=24$ ECUs from the project. If the four group members together contribute 10 ECUs to the project, you and all others will get a payoff of $10 \times 0.4=4$ ECUs from the projects.

\section{Your total income}

Your total income results from the summation of your income from the private account and your income from the project.

Income from the private account
$(=20-$ Contribution to the project $)$
$+\quad \begin{gathered}\text { Income from the project } \\ = \\ (=0.4 \times \text { Sum of contributions to the project }) \\ \text { Total income }\end{gathered}$




\section{Control questions}

Please answer the following control questions. Their purpose is to make your familiar with the calculation of the incomes that accrue from different decisions about allocation of 20 ECUS.

1. Each group member has 20 ECUs in his or her disposal. Assume that none of the four group members (including you) contributes anything to the project. What will your total income be? ECUs

What is the total income of the other group members?

ECUs

2. Each group member has 20 ECUs at his or her disposal. Assume that you invest 20 ECUs into the project and each of the other group members also invests 20 ECUs. What will be your total income?

ECUs

What is the total income of the other group members?

ECUs

3. Each group member has 20 ECUs at his or her disposal. Assume that the other three group members together contribute 30 ECUs to the project.

What is your total income if you - in addition to the 30 ECUs - contribute 0 ECUs to the project?

ECUs

What is your total income if you - in addition to the 30 ECUs - contribute 15 ECUs to the project? ECU

If you finish answering these questions before the others, we advise you to think about the additional examples in order to further familiarize yourself with the decision situation.

Part 1In the following experiment you will again be asked to make a decision as described above. You will again have 20 ECUs at your disposal and you have to decide how much you want to contribute to the project. The ECUs that you do not invest will be transferred to your private account. Your income will again be calculated as follows:

Income from your private account
$(=20-$ contribution to the project $)$
+
Income from the project
$=$
$(=0.4 \times$ Sum of contributions to the project $)$
Total income

The following experiment will be played for 10 rounds. You will therefore be asked to decide on how to invest your 20 ECUs 10 times in a row.

Before part 2 starts, all groups will be recombined by a random mechanism. That means that you will form a group with participants who you have not been in a group with before. A group consists of players A, B, C and D.

There are 2 types of group members: type $\mathrm{X}$ and type $\mathrm{Y}$. Type $\mathrm{X}$ players will always stay in a group while a type $\mathrm{Y}$ player changes groups after each round. The screen will inform you about your own allocated type as well as the types of the other members in the group.

Please insert into each input box how many ECUs you want to invest into the project and press "OK" to confirm. 
After each of your contribution decisions you will be asked to estimate how many ECUs each of your group members invested into the project.

The contribution table in which you will enter your estimates will look like this:

\begin{tabular}{|l|l|l|l|l|}
\hline Player & A & B & C & D \\
\hline Type of player & X & X & X & Y \\
\hline Estimate & YOU & {[]} & {[]} & {[]} \\
\hline
\end{tabular}

In addition, the program will indicate the average value of your estimates. Please confirm your estimates with "OK”.

If you make a good estimate, you will receive an income. This income is the result of 10 ECUs minus the deviation of your estimate and the actual average:

Income = 10 ECUs - |deviation|.

If your estimate was wrong by 10 ECUs or more, you will not receive any income. However, no ECUs will be taken from you, which implies that you cannot lose anything at this point.

Your income from the estimate will be transferred to your private account but you cannot invest these ECUs in the following rounds. Regardless of your estimate you will again have 20 ECUs in the next round that you can invest.

At the end of the second part a participant will randomly draw a piece of paper with a number between 1 and 10 from an urn. The number that is drawn indicates the round that will be payoff-relevant for this experiment. If for example a participant draws a piece of paper with the number " 3 " from the urn, your result from the third round is payoff-relevant.

Please raise your hand if you have any questions about the experiment, we will then come to you to answer your questions. When no more participants have any questions, we will start the computer program. Please wait quietly in your seat after you have made you decision as more tasks will follow shortly.

\section{Part 2}

In the third part of the experiment you will be asked to again decide on how to allocate the amount of 20 ECUs. Your income will be calculated in exactly the same way as in the second part of the experiment. You will again play for 10 rounds and asked to decide on how to invest your 20 ECUs 10 times in a row.

You will keep the same letter as in the experiment before, so if you e.g. were a Player 'B' during the last part, you will be again a player ' $\mathrm{B}$ '.

There will be again two types of players: type $\mathrm{X}$ and type $\mathrm{Y}$. Players of type $\mathrm{X}$ will be in the group as in the second part of the experiment. Players of type $\mathrm{X}$ will again stay in their groups. Players of type $\mathbf{Y}$ will change into a new group after each round. The screen will inform you about your own allocated type as well as the types of the other members in the group.

This experiment will also be played for 10 rounds. Between the rounds you will once again be asked to estimate how much the other group members contributed to the project. Your income for your estimate is calculated just as in the second part of the experiment.

After 10 rounds drawing a number from an urn will determine which of the 10 rounds will be payoff-relevant.

Please raise your hand if you have any questions about the experiment, we will then come to you to answer your questions. When no participant still has any questions we will start the computer program. Please remain silently in your seat after you have made you decision as more tasks will follow shortly.

\section{After the experiments}

You have now participated in all parts of the experiment. We now ask you to please fill in a short questionnaire at the computer. After filling out the questionnaire you will see a screen that will indicate how much earned altogether. Please remain silently in your seat until we call you. We will then pay you in cash. 


\section{Appendix II}

Figure A: Contributions over time in mixed treatments:

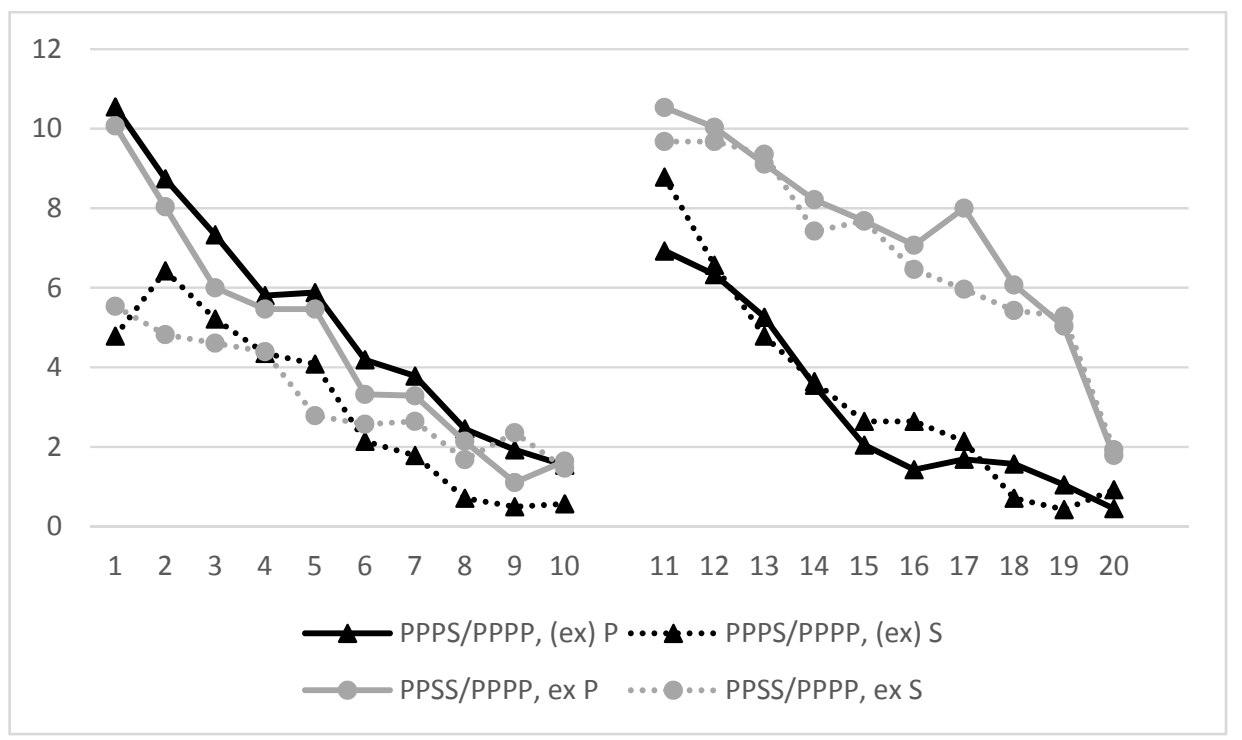

Figure B: Beliefs in mixed groups over all 20 rounds

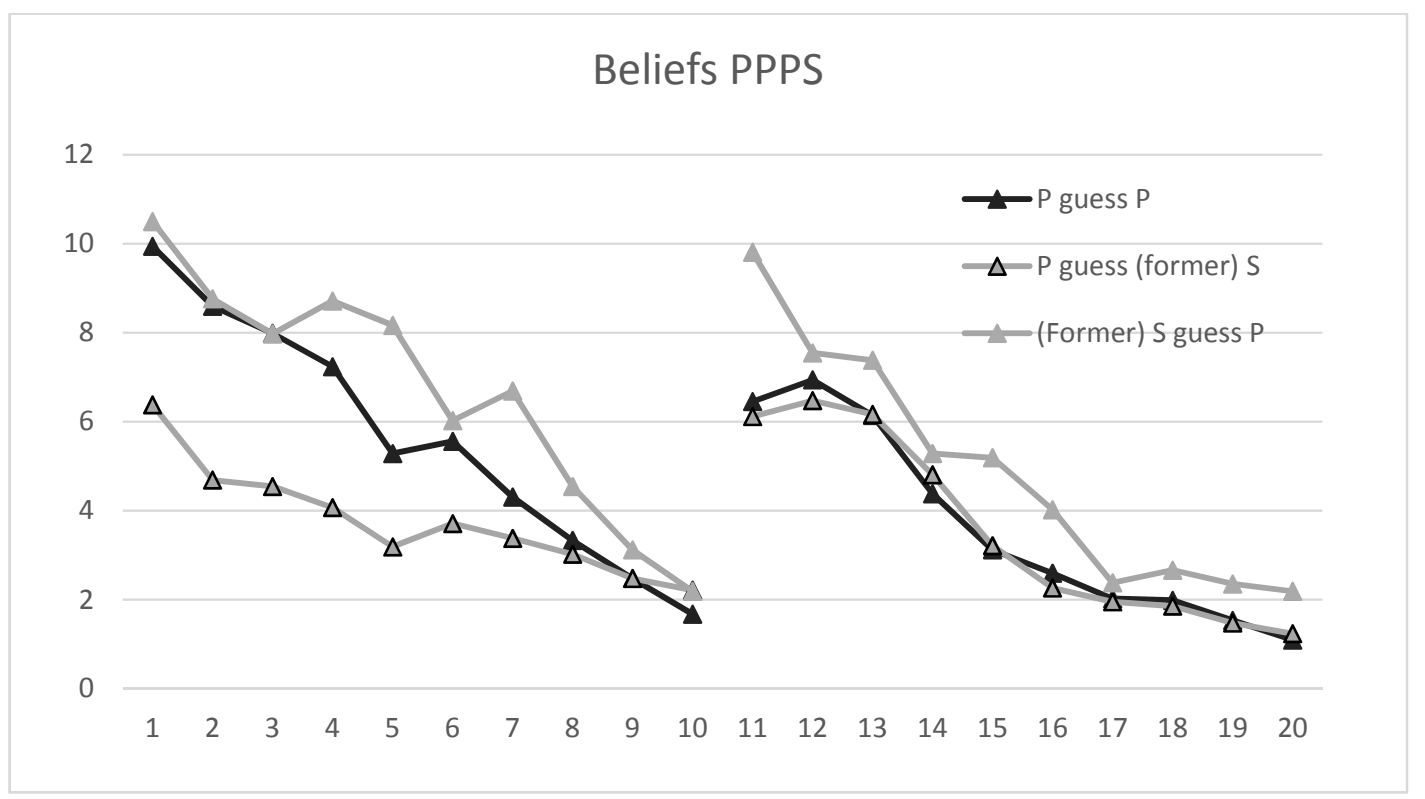


Beliefs PPSS

12

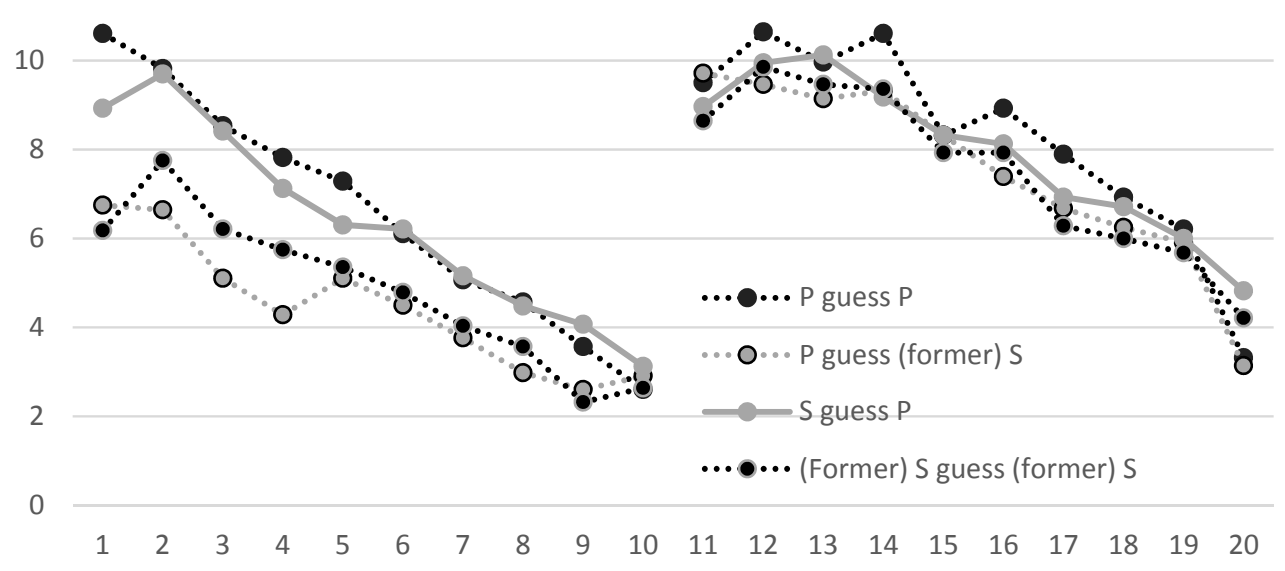

